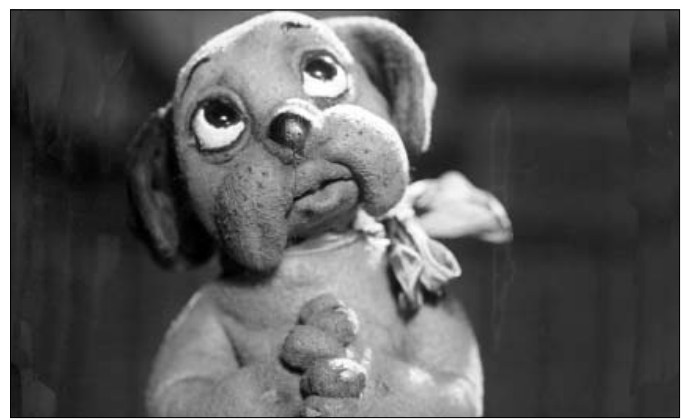

Fetysz maskotka Władysława Starewicza. Surrealistyczny film dla dzieci o problemach dorosłego świata

Przed śmiercią Starewicz popadł w całkowite zapomnienie. W latach 6o. styl jego animacji musiał wydawać się anachroniczny. Nowe tendencje w kinie lalkowym polegały na odejściu od realizmu w stronę umowności i symbolu. $\mathrm{Z}$ pisanych po wojnie Pamiętników wynika, że mimo wszystko wierzył $\mathrm{w}$ to, że dokonał w swoim życiu ważnych osiągnięć - jako pionier „ożywionej plastyki” i bezkompromisowy autor filmu lalkowego. Renesans jego twórczości przypada dopiero na lata 8o. XX wieku.

Wielu równie utalentowanych animatorów porzuciło przed wojną tę wymagającą profesję, gdyż nie mogli poradzić sobie z dużo mniejszymi przeciwnościami. Starewicza nie zniechęciły ani dwie wojny światowe, rewolucja i tułaczka po Europie, ani przełom dźwiękowy, po którym nastąpił bolesny kryzys ekonomiczny, ani nawet brak zainteresowania ze strony dystrybutorów i problemy finansowe. Do dziś jednak nie zdobył mistrz Starewicz rozgłosu, na jaki zasługuje jako autor filmów nie tylko zabawnych i znakomicie zrealizowanych, ale również głębokich, przesiąkniętych duchem humanizmu, odwołujących się do najlepszych tradycji sztuki europejskiej i ludowej. Wizerunek „tresera owadów” to zdecydowanie za mało.

\title{
Metodologia nowej historii filmu
}

\author{
MAREK HENDRYKOWSKI
}

Uniwersytet im. Adama Mickiewicza

\section{Wokół definicji}

Pierwsza polska definicja pojęcia filmowej nouvelle histoire została zaprezentowana w Słowniku terminów filmowych ponad dwadzieścia lat temu i brzmiała następująco:

światowy nurt refleksji historycznofilmowej dekady lat osiemdziesiątych skoncentrowany na rewizji tradycyjnej metodologii historii filmu, poszukiwaniu efektywniejszych procedur badawczych oraz na źródłowych badaniach dziejów kinematografii i sztuki filmowej prowadzących do ich nowego odczytania i reinterpretacji dotychczasowego obrazu historii filmu[1].

Nouvelle histoire (określenia synonimiczne: New Film History, nowa historia filmu etc.) w swojej międzynarodowej reprezentacji i wieloistnym zróżnicowaniu była wówczas kojarzona z nazwiskami takich badaczy historii kina, jak: Robert C. Allen, Douglas Gomery, Richard Abel, Michèle Lagny (wieloletnia redaktorka znakomitego paryskiego periodyku filmowego „Iris”), Noël Burch, Thomas Elsaesser, André Gaudreault, Tom Gunning, Charles Musser, Paolo Cherchi Usai, Michaił Jampolski, Jurij Cywjan (Yuri Tsivian), Richard Koszarski (zasłużony założyciel i lider amerykańskiego czasopisma „Film History”), Ben Brewster, Kevin Brownlow, a w Polsce - Alina Madej i Małgorzata Hendrykowska.

Charakterystyczną właściwością przytoczonej definicji nouvelle histoire jest jej, by tak rzec, programowo rewizyjny charakter. Nowa histo-

[1] M. Hendrykowski, Słownik terminów filmowych, hasło: nouvelle histoire, Ars Nova, Poznań 1994, s. 196. 
ria filmu niejako $\mathrm{z}$ założenia ma nie tylko tu i ówdzie uzupełniać i korygować ujęcia zaprezentowane przed wieloma laty przez poprzedników, ale także zbadać i kompleksowo opisać odkrywaną na nowo przeszłość kinematografii i sztuki filmowej w sposób całkiem odmienny niż uczynili to oni.

\section{Remanent zaszłości}

Skoro mówimy o nowej, czas przywołać na pamięć tę starszą, dziś już bardzo odległą. Dawna historia filmu wniosła ogromne zasługi, gros jej osiągnięć było jednak naznaczone skazą wyznawanej ideologii. Nie chodziło tylko o wyznawane wartości, lecz o tendencyjnie ukazany obraz dziedziny. Wpisane w opracowania: Georges'a Sadoula, Paula Rothy, Lewisa Jacobsa, Siegfrieda Kracauera, Lotte H. Eisner czy Jerzego Toeplitza, „postępowe” ujęcia dziejów kina i kinematografii jedne aspekty kina przez takie sprofilowane i wybiórcze podejście nadmiernie uprzywilejowywały, podczas gdy inne - w niezasłużony sposób spychały na margines.

Braci Lumière $\mathrm{z}$ ich fabrykanckim rodowodem i burżuazyjnym zapleczem skonstruowanego przez nich aparatu nie sposób było przedstawić inaczej niż z dystansem dla „niesłusznego" pochodzenia. Podobnie jak potentatów światowej kinematografii przed Wielką Wojną: Charles’a Pathé i jego odwiecznego rywala - Léona Gaumonta. Inni doświadczyli znacznie gorszego traktowania. David Wark Griffith, któremu sztuka narracji filmowej zawdzięcza tak wiele, okazał się twórcą nie tylko „wstecznym”, ale i „reakcyjnym” (apologeta Ku-Klux-Klanu). Buster Keaton, Ben Turpin i Harry Langdon figurowali jako szeregowi komicy, podczas gdy Charlie Chaplin pozostawał wielkim „postępowym” artystą.

Można tu wręcz mówić o tendencyjnej (zdeterminowanej ideologicznie) historii kina, której autorzy dokonują przedustawnych manipulacji wymową opisywanych przez siebie

[2] P. Rotha, The Film Till Now, Vision Press,

London 1949.

[3] L. Jacobs, The Rise of the American Film, Harcourt, Brace, New York 1939. twórczych dokonań i faktów. Nie chodzi bynajmniej o oczywisty w przypadku każdej historii filmu element wyboru własnych, takich a nie innych, kryteriów i preferencji oraz nieuchronnej subiektywizacji autorskiego spojrzenia. Idzie o co innego, mianowicie o generalne nastawienie historyka, który opisując dzieje kina, kieruje się przy tym - upozorowaną na dziejowy obiektywizm - określoną tendencją i trybem wyjaśniania podporządkowanym naiwnie pojętemu determinizmowi i ideologii dziejowego postępu.

Dochodzi do tego kolejna doniosła kwestia: wyboru takich a nie innych zjawisk artystycznych, które zostały przez danego historyka umieszczone w historycznej mozaice przywołanych, skomentowanych i zinterpretowanych przez niego faktów. Jednym $\mathrm{z}$ nich poświęca się w tych opracowaniach zbyt wiele uwagi, dla innych w ogóle zabrakło miejsca. Z dzisiejszej perspektywy okazuje się, że lista przecenionych w nich twórców i dzieł jest równie długa jak lista niedocenionych. Tym pierwszym poświęca się zbyt wiele uwagi, podczas gdy inni otrzymują jej stanowczo za mało, co rzutuje w konsekwencji na przedstawiony przez badacza obraz całości.

Nie znaczy to, że klasyczne historie kina i sztuki filmowej są dzisiaj opracowaniami bez wartości. Rzecz polega na czym innym, a mianowicie: na natrętnej w wielu momentach egzegezie poszczególnych dokonań kinematografii i sztuki filmowej (przykłady dobierane pod z góry przyjętą przez badacza ideologiczną tezę) oraz na braku alternatywności badawczego ujęcia. Ogromne niegdyś - nie tylko ograniczone do danego kraju, ale także międzynarodowe zainteresowanie tymi publikacjami sprawiło, iż były one wielokrotnie wznawiane i zostały przetłumaczone na wiele języków. Siłą rzeczy, książki te zyskały z czasem powszechnie przyjętą opinię dzieł kanonicznych.

Kolejną znamienną cechą dawnych pionierskich historii kina jest układ naczyń połączonych, jakie względem siebie stanowią. Ich uważna lektura porównawcza dowodzi, że określając rzecz eufemistycznie - bywały względem siebie źródłem daleko idącej inspiracji (dla przykładu: Paul Rotha[2], Lewis Jacobs[3], 
Georges Sadoul[4], Siegfried Kracauer[5], Lotte H. Eisner[6] w strawestowanym i w wielu partiach kompilacyjnym opracowaniu Toeplitza). W efekcie wytworzył się więc pewien nierewidowany kanon historii tej dziedziny, utrzymujący się w kolejnych replikach przez dziesiątki lat.

Zasługa wymienionych pionierów historii kina, której nie sposób przecenić, polegała w głównej mierze na przecieraniu szlaków. Wytyczając owe szlaki, gubili jednak po drodze z pola widzenia wiele wartościowych zjawisk, inne zaś niesłusznie deprecjonowali.

Najłatwiej wybaczyć poprzednikom rozmaite przeoczenia wynikające $\mathrm{z}$ fragmentaryczności źródeł, jakimi wówczas dysponowali, i braku dostępu do wielu filmów. Wystarczy porównać to, co wiemy dzisiaj przykładowo: o prehistorii kina, paradygmacie wczesnoniemego kina atrakcji, filmie dokumentalnym najstarszego okresu, początkach kinematografii brytyjskiej, najdawniejszych animacjach (Reynauda, Cohla i in.), o Mélièsie, Porterze, Griffithie, Feuilladzie, Alice Guy Blaché, Anicie Loos, filmowcach szwedzkich i włoskich, kinie przedrewolucyjnej Rosji czy Friedrichu Wilhelmie Murnau - z tym, co na ich temat można znaleźć w pierwszych dwu tomach Historii sztuki filmowej Jerzego Toeplitza. Podkreślam jednak, iż w tym przypadku korekta łączy się $\mathrm{z}$ pełnym usprawiedliwieniem.

Gorzej, kiedy osobiste upodobania bądź najczęściej idiosynkrazje powodują, że coś lub kogoś się eliminuje. Jeszcze gorzej, gdy podobnym demonstracjom towarzyszy czarny piar. Tak właśnie wygląda, niestety, skrajnie schematyczna historia polskiego kina dwudziestolecia międzywojennego zaprezentowana w drugim, trzecim i czwartym tomie Historii sztuki filmowej Toeplitza[7]. Na kartach tego pomnikowego skądinąd opracowania z przyczyn ideologicznych (ale nie tylko) niemal wszystko, co dotyczy naszego filmu w latach 1918-1939, zostało wyśmiane i potępione $\mathrm{w}$ czambuł $\mathrm{z}$ wyjątkiem kilku ambitniejszych twórców i tytułów. Jedynym wyjątkiem jest nadmiernie przeeksponowane znaczenie Stowarzyszenia Miłośników Filmu Artystycznego START i działań jego aktywistów jako jedynej godnej uwagi rodzimej inicjatywy tamtego okresu[8].

\section{Wyznaczniki nowej historii filmu}

Niełatwo jest wskazać wyróżniki stanowiące differentia specifica nowej historii filmu. Z pewnością nie będzie to jakiś jeden uderzający rys charakterystyczny. Spróbujmy jednak wskazać te znamionujące ją aspekty, które decyduja o jej zasadniczej odmienności metodologicznej względem historii klasycznych.

Po pierwsze, nowa historia nie jest już tylko historią filmu, lecz również historią kina, kinematografii jako medium, przemian języka ruchomych obrazów i kultury filmowej oraz audiowizualnej.

Po drugie, kwestionuje ona zasadność tradycyjnie stosowanych procedur opisu historycznofilmowego opartych na galerii sylwetek znakomitych filmowców i następstwie wybitnych dzieł, jakie stworzyli.

Po trzecie, neguje mechanistyczny tryb wyjaśniania poszczególnych zjawisk i procesów ewolucyjnych, będący pochodną determinizmu „konieczności dziejowej”.

Po czwarte, wykazuje zasadniczą nieufność wobec ujmowania dziejów kina w sztucznych kategoriach samoistnie dziejącej się teleologii.

Po piąte, przywiązuje dużą wagę do funkcjonalizacji wszelkich zjawisk i faktów jako zintegrowanych $\mathrm{w}$ ramach danego systemu elementów procesu historycznofilmowego.

Po szóste, dostrzega doniosłe znaczenie sposobów realizacji i projekcji (resp. techno-

[4] G. Sadoul, Histoire générale du cinéma, Flammarion, Paris 1946-1949.

[5] S. Kracauer, From Caligari to Hitler. A Psychological History of the German Film, Dobson, London 1947.

[6] L.H. Eisner, L'Ecran Démoniaque, André Bonne, Paris 1952.

[7] J. Toeplitz, Historia sztuki filmowej, t. 2: 19181928, Filmowa Agencja Wydawnicza, Warszawa 1956; t. 3: 1928-1933, Filmowa Agencja Wydawnicza, Warszawa 1959; t. 4: 1934-1939, Filmowa AgencjaWydawnicza, Warszawa 1969.

[8] J. Toeplitz, Historia sztuki filmowej, t. 3: 1928-1933, s. 394-402. 
logii ruchomych obrazów) jako czynnika inicjującego kolejne zwroty i przemiany nie tylko w kinematografii, ale także w kulturze filmowej i audiowizualnej.

Po siódme, neguje opartą na idei sukcesji, linearną koncepcję dziejów tej dziedziny jako łańcucha następstw i bezalternatywnego ciągu przemian zachodzących jedna po drugiej.

Po ósme, odmawia słuszności dotychczasowej wizji historii filmu wielkich autorów, podkreślając, iż - rozpatrywana $\mathrm{w}$ takim ujęciu - zależy ona od arbitralnie dokonanego na mocy decyzji badacza wyboru sylwetek reprezentujących a priori wybrane przez niego wartości.

Po dziewiąte, rewiduje i zmienia wcześniejszą definicję przedmiotu badań historycznofilmowych zorientowaną na tekstowy fenomen, jakim jest dzieło filmowe, wprowadzając $w$ to miejsce refleksję nad szeroko pojętymi kontekstami ewolucji kina i kultury filmowej.

Po dziesiąte, nie będąc dłużej historią wybitnych dzieł ani historią wielkich autorów należących do "głównego nurtu”, nowa historia kina dąży do pełnego rozpoznania alternatywnych zjawisk uczestniczących w jego przemianach (uważane przez poprzedników za margines historii kina: animacje, widowiska eksperymentalne etc.).

Po jedenaste, NFH (czyli New Film History) odrzuca obraz historii filmu tradycyjnie zdominowany przez kino fikcji, dążąc do równouprawnienia niefikcjonalnych form twórczości i komunikacji filmowej. Przywraca tym samym równorzędne wobec kina fikcji znaczenie jednemu $\mathrm{z}$ dwóch podstawowych rodzajów filmu, jakim jest kino faktów.

Po dwunaste, odrzucając ujęcia i wyjaśnienia o charakterze endogennym, nouvelle histoire wskazuje na kapitalne znaczenie zjawisk egzogennych jako czynnika stymulującego rozwój i katalizującego proces ewolucji tej dziedziny kultury.

Każdy z wymienionych powyżej aspektów okazuje się na swój sposób cenny i inspirujący

[9] R.C. Allen, D. Gomery, Film History: Theory and Practice, McGraw-Hill, New York 1985. poznawczo; żaden jednak nie może pretendować do miana kluczowego dla współczesnych sposobów i dróg uprawiania nowej historii filmu. Wydaje się, że ich wspólnym mianownikiem pozostaje dążenie do ponownego zbadania i odczytania przeszłości kina.

\section{Przeszłość na nowo odczytana}

Historia filmu nie jest pojęciem równoznacznym z przeszłością tej dziedziny. Można by ją metaforycznie określić jako przeszłość aktywowaną. Była ona tworzona wielokrotnie i powstaje ciągle od nowa. Nie jest przeto ani czymś stałym, ani tym bardziej raz na zawsze danym. Przechodząc nieustanne metamorfozy, stanowi jedną ze zmiennych form istnienia pamięci kina jako środka komunikowania (medium), systemu języka i dziedziny sztuki. Jak wszystkie inne formy pamięci kulturowej - zanika i obumiera. Od kilku dekad wymiana świadomości kina i sztuki filmowej, o której tu mowa, dokonuje się z niebywałym przyspieszeniem.

Opracowania sprzed dziesiątków lat należą dzisiaj do zabytków myśli filmowej. Nowa historia filmu zmierza do generalnego odnowienia kulturowej pamięci kinematografii. Dążenie to, pod warunkiem że poparte rzetelnymi odczytaniami źródeł, należy uznać za cenne i doniosłe. Nie sposób tego dokonać inaczej niż przez uwolnienie naukowej refleksji i oczyszczenie jej od dotychczasowych ujęć. Proces ten trwa od dłuższego czasu. Został on zapoczątkowany w latach 8o., a jego pierwszym doniosłym impulsem, symptomem i świadectwem stała się prekursorska książka Roberta C. Allena i Douglasa Gomery'ego Film History: Theory and Practice [9].

Historia filmu może być - jak nieraz już bywało $\mathrm{w}$ dawnych opracowaniach - historią autorów filmowych oraz historią dzieł przez nich nakręconych. Nie ulega jednak wątpliwości, że na takim jednoaspektowym i jedynie enumeracyjnym podejściu traci ona wiele ze swego potencjału poznawczego. Dostarcza bowiem materiału (skądinąd niezbędnych do budowy całości „cegiełek”), ale nie siatki pojęć, struktury, a zwłaszcza makrostruktury koncepcyjnej, któ- 
ra pozwala na nowo odkryć i odczytać głębsze sensy procesu ewolucji kinematografii, organizując badany materiał w całość wyższego rzędu.

Przede wszystkim jednak statycznie ujmowane, oparte na łańcuszkowym wyliczaniu, prezentacje dziejów filmu tracą z pola widzenia proces historyczny. Pomijają one przy tym - co jest ewidentnym błędem metodologicznym pierwszorzędnie istotny czynnik przemiany, bez której wszelka historia rozpada się na szereg niepowiązanych $\mathrm{z}$ sobą, zatomizowanych elementów, umownie nazywanych przez historyków „faktami”. Tak ukazywana historia filmu staje się narracją de facto ahistoryczną, pozbawioną czynnika procesualnego.

Przeszłość kina stanowi obiekt badawczy o bardzo wysokim stopniu złożoności. Jest ona wielonurtowym strumieniem rozmaitych zdarzeń - zarówno stricte filmowych, jak i okołofilmowych. Historyk kina tym różni się od dysponującego nieraz wspaniałą wiedzą szczegółową konesera, że ogarnia swą refleksją szerszą całość. Właściwe zadanie stojące przed historykiem filmu polega na wydobyciu (resp. rekonstrukcji) serii zjawisk symptomatycznych, a wraz z nimi - funkcjonalnego porządku, który sprawia, że pośród natłoku niezliczonych dzieł filmowych, w chaosie wszelkiego rodzaju faktów i mnogości poszczególnych epizodów mimo wszystko możemy jednak uchwycić istotne prawidłowości, które pozwalają je z sobą łączyć, strukturować i racjonalnie wyjaśniać poprzez opis, analizę i interpretację.

Do tego wszystkiego dochodzi jeszcze aspekt pragmatyczny, czyniący wiedzę historyka wiedzą wielorako potrzebną i przydatną (ergo stosowaną). Nowa historia filmu, której kolejne dokonania od kilku dekad obserwujemy zarówno w kraju, jak i na świecie, staje się przede wszystkim historią praktyki: artystycznej (film jako sztuka), dalej - komunikacyjnej (film jako język ruchomych obrazów) oraz społecznej i antropokulturowej (film jako medium), ergo - opisem i analizą zbiorowego doświadczenia w zakresie komunikowania się społeczeństw XIX, XX i XXI wieku za pośrednictwem ruchomych obrazów.
Przy udziale i w powiązaniu tych trzech aspektów nouvelle histoire uruchamia i rozwija narrację obejmującą najróżniejsze aspekty oraz historyczne konteksty owej indywidualnej i zbiorowej praktyki: rodzajowy, gatunkowy, tematyczny, produkcyjny, technologiczny, realizacyjny, dystrybucyjny, a także krąg zagadnień dotyczących recepcji rozmaitych odmian twórczości. Tak pomyślana i uprawiana, refleksja nad dziejami i przemianami tej dziedziny zmierza każdorazowo do modelowej rekonstrukcji szeroko pojętej - nieustannie zmieniającej się praktyki twórczej i komunikacyjnej stosowanej w danym stadium lub stadiach rozwoju kina.

Jeśli rzecz dotyczy jednego stadium (na przykład kinematografii polskiej okresu socrealizmu 1949-1953), to mamy do czynienia $\mathrm{z}$ historią rozgrywającą się wewnątrz granic pojedynczej synchronii. Notabene, każda $\mathrm{z}$ takich synchronii zawiera własną dynamikę rozwoju i właściwe ujęcie danego przebiegu wcale nie musi oznaczać statycznego potraktowania rozpatrywanego materiału historycznego wchodzącego w jej skład. Ujęcia synchronii rozwojowych - choć z natury rzeczy ograniczone do pewnych ram czasoprzestrzennych wcale nie są skazane na pominięcie przemiany. Wprost przeciwnie, właśnie dlatego mówimy w ich przypadku nie o synchronii, lecz właśnie o synchronii rozwojowej.

Jeśli natomiast przedmiotem zainteresowania badacza jest przemiana historyczna (przykładowo, obejmujący swym zakresem trzy kolejne stadia okres rozwoju polskiego dokumentu po wojnie do roku 1955), to w gre wchodzi - rozmaicie aranżowane przez narratora ujęcie diachroniczne. Świadomość głębokiego związku funkcjonalnego, który zachodzi między jednym a drugim, osiągnęła w przypadku dokonań historii filmu spod znaku nouvelle histoire o wiele wyższy poziom autorefleksji i dyscypliny badawczej niż ten, jakim dysponowali klasyczni historycy kina. Choć również i oni zdawali sobie sprawę z wagi tej - zasadniczej dla obrazu procesu historycznofilmowego - kwestii.

To, co nazywane bywa nową historią filmu, jest w gruncie rzeczy kolejnym stadium rozwo- 
ju - zapoczątkowanej w latach 30. XX wieku naukowej refleksji historycznofilmowej. Wbrew twierdzeniom o rewolucyjnym przełomie, jaki się na tym polu dokonał, doszło tutaj - podobnie jak w metodologii innych dziedzin nauki, przede wszystkim: lingwistyki, etnologii, literaturoznawstwa, nauk o kulturze, historii i psychologii społecznej - do reorientacji badawczej będącej wynikiem reformatorskiej krytyki ze strony samych historyków kina.

Dość szybko nowa historia filmu stanęła przed tymi samymi zagadnieniami i dylematami, które znacznie wcześniej były już udziałem pionierów tej dziedziny nauki. Dla Roberta C. Allena, Douglasa Gomery'ego, Michèle Lagny, Toma Gunninga, Charlesa Mussera, Jurija Cywjana, André Gaudreault, Richarda Abla, Thomasa Elsaessera i innych czołowych reprezentantów nouvelle histoire stało się jasne, że kluczowe znaczenie mają w tej przemianie: ponowne ustalenie przedmiotu i zakresu badań, źródłowy charakter wszelkich ustaleń, relacja między „tekstem” a „kontekstem” oraz poszerzenie obszaru mapowania studiowanych zjawisk.

Ilekroć mamy na uwadze dylematy metodologiczne nowej historii filmu, daje o sobie znać sprzężenie zwrotne i nieustanne napięcie pomiędzy:

1) hipotezą a jej filmograficznie (resp. źródłowo) uargumentowanym potwierdzeniem;

2) aspektem faktograficznym (precyzyjny opis ciągle poszerzanego zasobu źródeł), z jednej strony, oraz aspektem analityczno-interpretacyjnym - z drugiej;

3) badanym zjawiskiem - należącym zarówno do systemu kultury filmowej, jak i do makrosystemu kultury - a jego historycznofilmowym wyjaśnieniem.

Reorientacja nowej historii filmu dotyczy zatem generalnie trzech - wielorako powiązanych z sobą - podstawowych kwestii: primo - poszerzenia bazy wykorzystywanych źródeł (pozyskiwanie nowych źródeł, rewizja dotychczasowych, kapitalna rola archiwów filmowych i nowych technologii); secundo - zmian w zakresie metodologii badań historycznofilmowych (tu redefinicja przedmiotu badań, pociągająca za sobą zmianę horyzontu badawczego); oraz tertio - kompleksowego ujmowania badanych zjawisk w kategoriach najszerzej pojętych tekstów kultury (fenomeny nie tylko sztuki filmowej, ale również filmu, kina etc.). Są one odczytywane i rozpatrywane jako elementy systemowe, wchodzące w skład makroprocesu przemian kultury i sztuki XIX i XX wieku.

Pozostaje na koniec ważne pytanie: czy jest możliwa - to znaczy realnie osiągalna - absolutnie kompletna, definitywna historia filmu? Innymi słowy: czy coraz to nowe, niekiedy rewelacyjne, odkrycia badaczy i nieustannie dokonywane przez nich kolejne historycznofilmowe rewizje, przewartościowania i reinterpretacje złożą się ostatecznie na nową, pełniejszą niż kiedykolwiek historię kina? W gruncie rzeczy zapytaliśmy o wielkie marzenie kilku pokoleń historyków tej dziedziny. Marzenie zawierające w sobie myśl o powołaniu do życia tak wartościowej i odpornej na wpływ czasu historii kina i dziejów sztuki filmowej stanowi nie od dzisiaj idée fixe niejednego badacza-polihistora. Marzenia są po to, by je mieć i próbować urzeczywistniać.

$\mathrm{Z}$ drugiej strony, dążenie do ich realizacji nie wyklucza postawy sceptycznej. Pełna historia filmu nie wydaje się realnie możliwa i zapewne nigdy nie zostanie osiągnięta. Mimo to, marzeń o niej nie należy porzucać i powinno się je mieć stale na uwadze. Zbliżać się do nich nieustannie. Marzenia $\mathrm{z}$ istoty swej bywają nierealne i najczęściej pozostają nieosiągalne, ale - jeśli jest się profesjonalnym historykiem filmu - warto zaprzątać sobie nimi głowę i usilnie starać się o ich urzeczywistnienie. 